how many disorders there are, or how many names there are for similar if not quite identical disorders. An overview by the editors would have been helpful, although not a substitute for firm editorial directives to the authors in the first instance. This, however, is a small quibble. The text offers an up-to-date authoritative account of the field that should be an excellent source of reference for some years to come.

\section{A Colour Atlas of Bone Disease}

By Victor Parsons. Pp. 112, illustrated. Wolfe Medical Publications, London, 1980. $£ 14.00$.

The main problem for anyone wanting to produce a book on bone disease for clinicians is that osteologists are not an identifiable species. The author, in a small book, has attempted to satisfy us all and, not surprisingly, has not succeeded. The inherent problem is compounded by a deliberate cmphasis on histology which, regrettable though it may be, most clinicians find a bore. Photomicrographs which are too small to show detail and have inadequate legends do not help. Unhappily the radiographic reproductions suffer the same fate. Added to this there are 2 chapters on History Taking and Examination, possibly aimed at medical students or postgraduate examination candidates, the illustrations of which are sometimes duplicated in the later chapters. There are 2 pictures of neurofibromatosis within a few pages of each other, and a number of other pictures such as a black and white one of a post-mortem pancreas, that are neither aesthetic nor instructive.

The text is tight and accurate but the illustrations, on which any atlas may depend, add remarkably little to it. Although most clinicians would get something of value out of the book it cannot be warmly recommended.

\section{The District Administrator in the National Health Service}

By Rosemary Stewart, Peter Smith, Jenny Blake and Pauline Wingate. Pp. 211. King Edward's Hospital Fund for London, London, 1980. £7.50.

This book records observations and comments, of 4 research workers, on the role, work and attitudes towards management of a selected number of district administratros and single district area administrators. An important reason for embarking on the research was to identify training needs, but it might be questioned whether this was achieved in sufficient depth. There are perhaps as many versions of the district administrator's job and responsibilities as there are district administrators, and any analysis should be in much greater detail, and recognize the interrelation between area activities (or lack of them) and the affairs of the district.

The chapter on training was tantalizing, for it could have said so much more than it did. The authors are quite right to emphasize the need for help in man management. This, however, needs considerable enlargement as the National Health Service is still remarkably confused as to who should do what and how one person should relate to another. The most important point made by the authors is that the district administrator should always be assessing the content and process of the service that he is providing. In other words, he should consciously aim to make certain that subordinates fill the gaps that his style of administration leaves. Not surprisingly, however, this begs the question of the elaborate selection process.

The various approaches a district administrator apparently has to his subordinates were identified as 'joining, supporting, monitoring, separate'. These concepts must be seen against the background of the demands, constraints and choices of the district administrator's job, all of which are carefully considered in this study.

One comment in the text is that the demand element is a comparatively small part of the job, with a wide variety of choices. This goes a long way to explaining the statement that most district administrators (some may think surprisingly) found that the satisfaction of the job outweighed the frustrations.

There are many fascinating observations in this book which should give rise to endless discussions, and a review cannot do justice to the various analyses of the district administrator's role in relation to the district management team, to other functions and to his own concept as a manager. Thought should seriously be given to the level of some of the district administrator's activities described, where actions were confused with those of a hospital secretary, or in some instances of a personal secretary or clerk. The book is completely specialist in nature and undoubtedly strives, almost too hard, to be objective. It is recommended to all who are involved in or wish to obtain a better understanding of Health Service administration at the district level.

\section{Essentials of Neurosurgery}

By Richard Hayward. Pp. 275, illustrated Blackwell Scientific Publications, Oxford, 1980. £9.75 (paperback). The book is a soft back, has 272 pages and is a useful size to be carried about; it is well classified and indexed and will be a useful reference for junior doctors. There are numerous illustrations, most of which are extremely helpful, but there are a few which are somewhat confusing. Although it contains all the essentials of the management of neurosurgical patients, the urgency with which certain forms of treatment should be administered is not sufficiently emphasized, particularly in the chapters on head injuries and spinal injuries, presumably this is corrected in Mr Hayward's book on the management of head injuries. He has summed up the present concepts in most topics and provides the reader with a clear outline of neurosurgical pathology and its management. The chapters on tumours and hydrocephalus are particularly well presented.

It is a book I would heartily recommend for house officers, accident and emergency room physicians, and useful reading for those preparing for postgraduate medical and surgical examinations. It will be marred for some by glaring spelling mistakes, which should have been eliminated during the preparation of the manuscript by the publishers of the book.

\section{Gynaecology by Ten Teachers}

Edited by S. G. Clayton, T. L. T. Lewis and G. Pinker. Pp. $x+385$, illustrated. Edward Arnold, London, 1980. £10.75.

Sixty years after the publication of the first edition, 'Ten Teachers' continues, despite changing contributors, to maintain the high standard which has come to be expected of it.

The reviewer has been impressed by the depth of coverage, the clarity of explanation and the topicality of content. Easy to read, frce of personal bias despite the multiple authorship and clearly set out, this book carries authority and must remain in the fore-front of student textbooks of gynaecology and can be unreservedly recommended.

\section{Holland and Brews Manual of Obstetrics}

By Robert Percival. 14th ed. Pp. xviii +876 , illustrated. English Language Book Society and Churchill Livingstone,

Edinburgh, 1980. $£ 20.00$ (low-priced edition $£ 6.00$ ).

First published in 1906, Holland's Manual of Obstetrics has now reached its 14th edition and has been thoroughly revised and partly re-written by Robert Percival and his collaborators.

New material in the current edition includes methods of study on fetal ecology, the use of ultrasound in obstetrics, the effects of medication on mother and fetus, the active

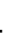
\title{
㤎
} . 
management of labour and obstetric problems of immigrant women. There are also sections on the fetus and the newborn infant. The chapter on tropical obstetrics by Lawson is of great interest, discussing problems peculiar to these areas which are quite outside the experience of anyone who has worked only in western Europe and emphasizes the disadvantages under which medical and nursing staff have to work.

One great advantage of a textbook which has successfully survived so many editions is that techniques or methods of management which have largely been superseded are still included for reasons of completeness or comparison. This is particularly true of operations, in particular destructive operations on the fetus for, although rarely required, it is reassuring to be able to refer to these for the occasion when required.

This is an encyclopaedic, comprehensive and well written book which is more than adequate for the postgraduate student and a useful source of reference. The book under review is a low-priced edition published in soft-back form and, as such, represents excellent value at this price.

Prostate Cancer. A series of Workshops on the Biology of Human Cancer. Report No. 9 UICC Technical Report Series, vol. 48

Ed. by Donald S. Coffey and John T. IsaACs. Pp. 289, illustrated. International Union Against Cancer, Geneva, 1979. Sw. Fr. 20.00

Carcinoma of the prostate is the third commonest cause of death from cancer in the male and indeed evidence of carcinoma may be observed in something like one-third of prostates at post-mortem of men over 40 years of age, most of which, of course, are latent prostatic adenocarcinomas which grow very slowly or may never express clinical manifestations. It is not surprising, therefore, that there is an immense amount of both clinical and basic research engendered by this important topic, particularly since it is one of the few tumours that is hormonally dependent.

Prostate Cancer is the paper-back report, in typescript production, of a Workshop on prostatic cancer held in Geneva in October 1978 under the auspices of the International Union Against Cancer. It represents the deliberations of 12 experts, coming from the U.S.A., U.K., Belgium, Germany, Holland and Switzerland with specialities ranging over the fields of urology, endocrinology, pharmacology, biochemistry and pathology. The 15 chapters deal with the endocrine factors controlling normal prostatic growth and function, prostatic anatomy, the morbidity and mortality of prostatic cancer, animal models of the disease, treatment and therapeutic trials. There is an extensive discussion of the staging of prostatic cancer and methods of objective evaluation of response to therapy in an attempt to provide base lines for co-operative studies. Each chapter carries an extensive and up-to-date bibliography.

This is a volume that cancer specialists and urologists will turn to for up-to-date information on this important field. However, it is concentrated stuff and will not appeal to the casual reader!

\section{Recent Advances in Gastroenterology}

Edited by I. A. D. Bouchier. Vol. 4. Pp. ix +347 , illustrated. Churchill Livingstone, Edinburgh, London and New York, 1980. $£ 16.00$.

Consolidation of knowledge rather than conceptual innovations would seem to have characterized the last 4 years in the field of gastroenterology. In a series of thoroughly referenced articles, Professor Bouchier has drawn together contributions from Britain and America to cover 10 areas of current interest. These surveys touch on most aspects of gastrointestinal disease, taking account of the application of newer investigative techniques and advances in those basic sciences which relate to the gut. The latter approach is particularly illuminating in the section on the oesophagus which is now clearly shown to be integrated into the upper alimentary tract through neurological and hormonal mechanisms. The chapter on the stomach and duodenum, on the other hand, recognizes the paucity of recent advances of our understanding of diseases of this region, it concentrates instead on a most extensive review of progress in the medical and surgical treatment of peptic ulcer. The arguments as to whether to advise cimetidine intermittently at high dosage, semipermanently at lower dosage, or to advise elective surgery (proximal gastric vagotomy) for duodenal ulcer are thoroughly discussed in the light of recent trials. The colon is shown to be emerging from its obscurity at the nether regions of physiological research. Transit times, motility and bowe habit are, of course, revisited but absorption studies, shortchain fatty acid metabolism, microflora and gas production, and endocrine status are all seen to be growth areas. Disenchantment with carcino-embryonic antigen is justified, while the association between clostridial endotoxin and pseudomembranous colitis is accepted.

It is reassuring to note that the perennial problem of distinguishing ulcerative colitis from Crohn's disease still requires a measure of clinical experience. The aetiology of Crohn's disease remains unknown despite some attractive hypotheses. Experimental models for ulcerative colitis have implicated immune complexes and $\mathrm{T}$ cell mechanisms i pathogenesis. Treatment is evaluated and the importance o preventing growth retardation in children emphasized.

Hepatologists are well represented in 3 chapters. One provides a clear review of the complicated serology and epidemi ology of the hepatitis $A, B$, non-A and non-B viruses. further section covers diagnostic approaches to liver dis: orders, chronic active hepatitis, the treatment of hepatic encephalopathy, drugs (including alcohol) and the liver and liver tumours. In the third chapter, on the gall bladder and biliary tract, exciting changes are described, heralded by developments in radiology, ultrasound and endoscopy, and the expansion of knowledge concerning gall stone formation and dissolution using chenoseoxycholic acid.

The pancreas features in an analysis which specifically excludes the endocrine aspects of its function. The section concentrates most usefully on the morphological and functional investigation of pancreatic disorders. The theoretical validity of the traditional advice to 'rest' the pancreas in acute pancreatitis is questioned again; however, alternatives such as the use of protease inhibition or pharmacological resting agents (e.g. glucagon) remain unconvincing. No book of advances in this field would be complete without a comment on endoscopy, although it is the shortest review in the book, having already infiltrated many other sections. Its diagnostic role continues to expand with the use of transgastroscopic ultrasonography. Its developing therapeutic function is analysed particularly as a delivery system for various imaginative devices including lasers which inevitably attract attention. The book concludes with a review of aspects of paediatric gastroenterology, notably hepatic disorders, gastrointestinal protein intolerance and selective inborn errors of absorption.

In summary, this work is a mine of information, the style is readable and direct, the bibliography is extensive and the index adequate. Jt will be of use both to those working specifically in these fields and to the busy general physician wishing to browse through a well presented account of gastrointestinal subjects of current interest. 